\title{
Riding the Tide of Oil Revenue Cyclicity: Enhancing Public Investment Management Efficiency in Ghana
}

\author{
Tuan Minh Le (Corresponding Author) \\ The World Bank, 1818 H Street, NW, Washington, DC 20433, USA
}

Tel: 1-202-473-8485 E-mail: tle@worldbank.org

Serdar Yilmaz

The World Bank, 1818 H Street, NW, Washington, DC 20433, USA

Tel: 1-202-473-935_E-mail: syilmaz@worldbank.org

\begin{abstract}
Smile Kwawukume
The World Bank, German Embassy Compound, Oldest Congo Town, Monrovia, Liberia

Tel: 231-886749203Ｅ-mail: skwawukume@worldbank.org
\end{abstract}

Received: June 20, 2016 Accepted: June 30, 2016 Published: August 2, 2016

doi:10.5296/csbm.v3i2.9800ＵRL: http://dx.doi.org/10.5296/csbm.v3i2. 9800

\begin{abstract}
Popular expectations for more public infrastructure services (i.e., hospitals, schools, roads) run high in Ghana because of recently discovered major oil and gas reserves in its' offshore deposits. However, Ghana doesn't have a good track record of using natural resource revenues, be it gold or cocoa, efficiently and effectively for development. The hard fact is that despite significant gold and cocoa revenues, the country has always experienced chronic infrastructure "deficit." It is unclear if the surge in oil revenues did translate into better development outcomes, whereas the sharp drop in oil prices would translate into more prudent allocation and use of capital budget. Weak and politicized public investment (PIM) system in Ghana exacerbates the potential cyclicality problems of natural resource revenues. To avoid these double traps of weak institutions and cyclicality, Ghana should find an appropriate strategy to "invest in the capacity to invest." This paper employs an indicator based framework developed by Rajaram et al. (2010) to explore efficiency and efficacy of Ghana's PIM system. Our diagnostic assessment indicates that a number of critical functions
\end{abstract}




\section{Macrothink}

Case Studies in Business and Management

ISSN 2333-3324

2016, Vol. 3, No. 2

in the Ghanaian PIM system, such as project proposal screening, appraisal, monitoring and evaluation, either exist only on paper or are completely missing.

Keywords: Public Financial Management, Ghana Public Investment Management, Infrastructure Investment, Economic Development, Infrastructure Financing 


\section{Introduction}

Traditionally known as the Gold Coast of Africa, Ghana has been the second largest gold producer in the region. In addition to gold, the country discovered major oil and gas reserves in its offshore deposits recently. As of 2009, its Jubilee field, among the first to be extracted, was estimated to hold 490 million barrels of high-quality oil with commercial exploitation expected to produce 120,000 barrels daily. (Note 1) The discovered reserves over their lifetime could amount to $\$ 37.5$ billion.

Despite her high potential to raise natural resource revenues for development needs, Ghana has always experienced chronic infrastructure "deficit." Currently a significant portion of public investments are supported by external donors. With the oil revenues coming on stream, this trend is changing and capital investments are being financed through budgetary funds coming from oil revenues. For example, the Parliament in 2011 approved a Master Facility Agreement (MFA) for US\$3.0 billion with the China Development Bank as part of the "oil for infrastructure" deal. The agreement defines the financial terms and conditions under which the Government of Ghana could borrow to finance various public investment projects. If managed effectively, these investments are potential contributor to sustainable growth and to the achievement of Ghana's development objectives. Sustainable growth will enable the companies to grow more quickly and to increase their market shares while being aware of the long- and short-term environmental impacts of their activities (Riasi \& Pourmiri, 2016). Public infrastructure investment raises output in both the short and long term, particularly during periods of economic slack and when investment efficiency is high (IMF, 2014. World Economic Outlook). Studies have shown that public investment drives will be more likely to succeed if governments take analytical issues seriously and safeguard their decision process against interests that distort spending decisions (Warner, 2014).

In Africa, an important component of the fiscal policy is public infrastructure investment which is central to economic growth. For African economies to be competitive, there needs to be investments in infrastructure to boost the productivity of their economies and to close the infrastructure gap. However, fiscal policies of African economies are also pro-cyclical (Thornton, 2008; Lledo, Yackovlev, \& Gadene, 2011). Like many other natural resource rich African countries, Ghana faces the challenge of translating prospective wealth beneath the ground to productive assets above the ground. International experience suggests that most of the developing countries rich in oil, gas, and mining resources face the same challenge (Barma, Kaiser, Le, \& Vinuela, 2012). The non-renewability and volatility of natural resource revenues pose numerous challenges for medium-term expenditure management. Without strong public investment system, the cyclicality of revenue flows through booms and busts would dictate the cyclicality of investment expenditures-which ultimately translate into incompleteness of project as well as delays, waste of resources and corruption in projects. High efficiency of public investment ultimately boosts the national output (Abaid, Furceri, \& Topalova, 2015). In countries where the public sector capacity is very weak, the discovery of natural resources exacerbates political economy problems and impacts the quality of capital spending process. Ghana is no exception and does not have good track record in avoiding such a trap. 
This paper employs an indicator based framework developed by Rajaram et al. (2010) to help Ghana in finding an appropriate strategy to "invest in the capacity to invest" (Collier \& Venables, 2008). It explores the efficiency and efficacy of Ghana's public investment management system. The paper is structured as follows. Section II introduces research methodology and data. Section III analyzes the institutional and procedural setting of the Ghanaian PIM, its strengths and weaknesses. Section IV concludes with policy implications.

\section{A Framework for Diagnostic Assessment of Public Investment Management Systems (PIM): Research Methodology and Data}

The PIM analysis framework developed by Rajaram et al. (2010, 2014) provides a pragmatic and objective diagnostic approach to assess the effectiveness of a public investment system. It focuses on institutional and procedural arrangements that relate to three main dimensions of fiscal policy making:

- $\quad$ Aggregate fiscal discipline: How much to spend/save?

- $\quad$ Allocation to sectors: Where to spend?

- $\quad$ Program efficiency and effectiveness: How to spend effectively and efficiently?

The diagnostic framework focuses on eight key critical dimensions of PIM (see Figure 1): (i) investment guidance, project development, and preliminary screening; (ii) formal investment appraisal; (iii) independent review of appraisal; (iv) project selection and budgeting; (v) project implementation; (vi) project adjustment during construction period; (vii) facility operation; and (viii) project evaluation. The framework tries to answer the following questions:

- Is there a credible link between project formulation and development strategy at the stage of preliminary screening?

- Is the appraisal process sufficiently rigorous? Does the same process apply consistently across projects of similar scales?

- $\quad$ Are there effective budget and procurement processes to support implementation and operation?

- $\quad$ Are there mechanisms for maintenance of productive assets?

In the analysis, we focus on government capital expenditures, rather than on the broader and less well defined concept of investment expenditures. In a cash accounting framework (GFSM, 1986), capital expenditures include payments for the acquisition of fixed capital assets, which are goods with a normal life of more than a year, and with more than a minimal significant value. Acquisition of fixed capital assets incorporates own-account capital formation i.e., construction by government itself of fixed assets, and also includes major renovations, reconstructions, or enlargements of existing fixed assets (as opposed to the costs of maintenance and repair of fixed assets, which are defined as current expenditures). In an accrual accounting framework (GFSM, 2001), capital outlays are transactions in 
non-financial assets, and the focus here is on fixed assets (assets used repeatedly in production processes that provide services for longer than one year).

This study is based on several tools, including (i) a diagnostic framework for PIM, (ii) institutional analysis, and (iii) direct collaboration with the multiple stakeholders, including government officials, the private sector, and other development partners. We draw upon a wealth of information from our direct interviews in the field, and secondary sources including existing literature produced by the Government of Ghana and development partners. The key findings presented in this paper have been drawn from our effort to move beyond anecdotal evidence and, to the extent possible, combine qualitative assessments with more quantitative data and evidence.

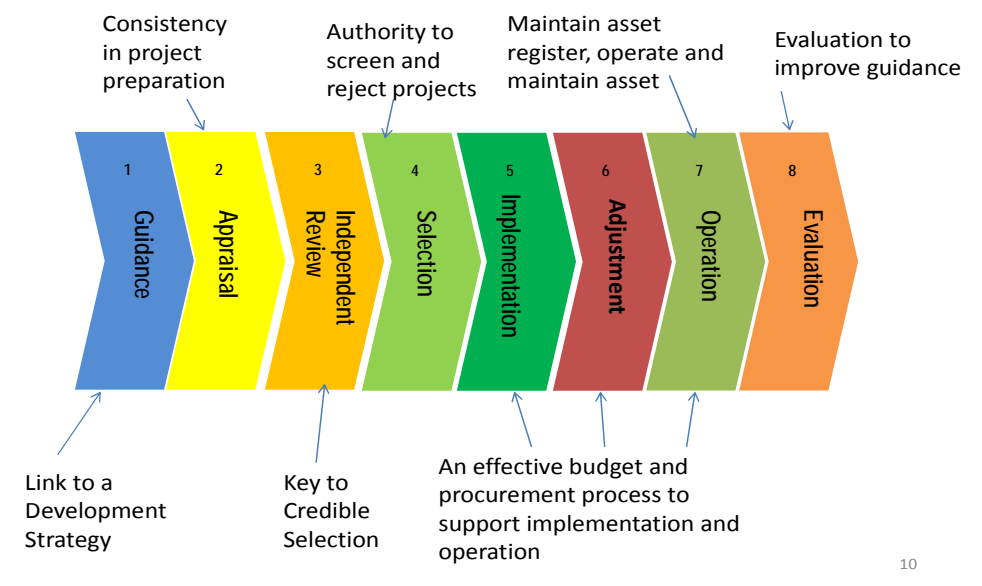

Figure 1. "Value chain” approach to diagnostic assessment of PIM

\section{Diagnostic Assessment of the PIM in Ghana}

The medium-term national development policy framework, Ghana Shared Growth and Development Agenda for 2010-13 (GSGDA), highlights the need for addressing large infrastructure gaps (for a total amount of US\$12.9 billion over the 4-year period) as a prerequisite for assuring Ghana's long-term growth and sustainable development. (Note 2) In the recent past, a significant portion of public investments in Ghana were supported by Official Development Assistance (ODA), according to donors' project preparation requirements. (Note 3) With Ghana now being a lower middle-income country, it is expected that investments will increasingly be financed by domestic funding sources, including non-concessional loans, (Note 4) and thus managed within national public investment management (PIM) framework. It is, therefore, critical to ensure that such framework is robust enough to effectively deliver infrastructure services to citizens, through sound planning, formulation, allocation and supervision (including O\&M) of public investments. Improvements in PIM could significantly 
enhance the efficiency and productivity of public investment (IMF. 2015. Making Public Investment More Efficient).

\subsection{Recent Public Financial Management Reforms in Ghana}

Ghana has a checkered history of public financial management (PFM) reforms. The recent efforts focused on enactment several legislations, the Financial Administration Act (FAA, 2003), the Financial Administration Regulations (FAR, 2004), the Public Procurement Act (2003), the Audit Service Act (2000), and the Internal Audit Agency Act (2003). These PFM reform efforts produced varied results. On the one hand, the Public Procurement Act clarifies for the first time how various public procurement practices can be conducted by state institutions and established the Public Procurement Authority as an overarching regulating body in this respect. The reform also resulted in the enactment of the organic law on public finance in December 2003 and the law on internal auditing. On the other hand, reform efforts in budgeting, accounting and recording were less than successful. A notable example of difficulty in reforming budgeting practice has been in financing of the Government's policy priorities, as reflected in the misalignment between Poverty Reduction Strategies' expenditure allocations and Budget appropriations. For example, in 2009, although overall resource allocation to implement Ghana's second Growth and Poverty Reduction Strategy has exceeded the resource requirements envisaged by the National Development Planning Commission by 44 percent, the budgetary allocations re-prioritized expenditures favoring activities in the Private sector Competitiveness and Good Governance thematic areas (see table 1), at the expense of Human Resource Development.

In 2010, the Government of Ghana has launched the Ghana Integrated Financial Management Information System (GIFMIS), a donor supported project. As part of the GIFMIS project, the Ministry of Finance and Economic Planning (MoFEP) is developing of a public investment program (PIP) in conjunction with the National Development Planning Council (NDPC). Software is being developed to build and maintain a database of project proposals in the PIP. Although it is too early to judge the success of these recent reform efforts, it is fair to say that they have important bearing on PIM.

Table 1. Resource allocation to finance medium-term plan (US\$ million)

\begin{tabular}{|l|l|l|l|l|}
\hline GPRS II Areas & $\begin{array}{l}\text { Private Sector } \\
\text { Competitiveness }\end{array}$ & $\begin{array}{l}\text { Human Resource } \\
\text { Development }\end{array}$ & $\begin{array}{l}\text { Good } \\
\text { Governance }\end{array}$ & Total \\
\hline GPRS Costing & 634 & 1,043 & 197 & 1,874 \\
\hline 2009 Approved Budget & 1,161 & 797 & 752 & 2,710 \\
\hline
\end{tabular}

\subsection{Analysis of "Must Have”Features of the Ghanaian PIM System}

In this section, we analyze "must-have" features of the Ghanaian public investment management system based on a diagnostic framework developed by Rajaram et al. (2010). We focus on eight critical dimensions (see Figure 1) as well as the efficiency and efficacy of 
the overall system and inter-linkages between different components of the system.

\subsubsection{Investment Guidance and Preliminary Screening of Projects}

According to the diagnostic framework, some broad strategic guidance for public investment is important to anchor government decisions and to guide sector-level decision-makers. In Ghana, the GSGDA for 2010-2013 was developed for government agencies to use as guidance in preparation of their public investment proposals. In addition to the GSGDA, the NDPC issued guidance notes to sector ministries, metropolitan, municipal and district assemblies (MMDAs) for the development and costing of sector strategies which are supposed to guide the annual budget preparation and the initiation of public investment proposals. Based on sectoral and sub-national medium term plans, annual work plans are prepared and fed into the three-year rolling medium term expenditure framework (MTEF).

Nevertheless, at the current stage, there is no established process for screening of project proposals, except for the public private partnership (PPP) proposals which are reviewed by the newly established Public Investment Department (PID) of the MoFEP. The weakness of the preliminary screening stage is the inadequate quality of strategic documents and the slow progress in implementation of the MTEF. The costing of sector strategies and their alignment to the budget remain weak. The MoFEP notes that while spending agencies across the board refer to the GSGDA in their programming and planning for capital expenditures, their strategic documents do not adequately address the issue of prioritization of budgetary decisions. (Note 5)

The divergence between strategy-planning and budgeting is rooted in the low quality of costing of sector strategies, which in turn suggests that the link between sector development plans and budget alignment is not very well established. Policy based budgeting is being piloted but the implementation is severely constrained as the basic prerequisites of budget credibility and a credible macro-fiscal framework are missing. As a result of these weaknesses, Ghana received a Public Expenditure and Financial Accountability (PEFA) score of $\mathrm{C}+$ as an overall rating for the indicator of "multi-year perspective in fiscal planning, expenditure policy and budgeting” in 2010 and again in 2013.

\subsubsection{Formal Project Appraisal}

The diagnostic framework suggests that projects or programs that meet the first screening test should be subject to the appraisal of their viability which requires the undertaking of feasibility analysis. In Ghana, project appraisals follow different procedures depending on the source of financing: donor-financed projects follow the donor-specific procedures and government-financed projects follow the Government's procedures. As our main focus in this paper is to analyze the public investment system, we focus only on government-managed projects.

The government's project appraisal system is highly decentralized without established formal rules. MDAs are vested with a full range of responsibilities of preparing, appraising and selecting their own projects in accordance with the budget guidelines. The inadequate regulatory framework combined with weak institutional capacity at both the central and 
MDAs' levels in appraisal pose the critical challenge to MoFEP’s “gate keeping” function.

Moreover, the MoFEP has issued multiple and conflicting guidelines for budget preparation, public borrowing and project selection. The Guidelines for the Preparation of the 2010-2012 Budget Proposals (dated 27 July 2009) makes a specific reference to a Capital Budget Committee to develop and implement a more rigorous approach in appraising capital expenditure projects. (Note 6) However, the Committee has, as of March 2012, not been set up. Furthermore, the reference to the Committee and proper review of funding requests for infrastructure projects have been dropped in the subsequent guidelines for the 2011-2013 and 2012-2014 budgets. Sections 6.18 and 6.19 of the Guidelines for the 2011-13 Budget Preparation requests a detailed list of information as well as an implementation plan from MDAs for their investment projects. However, it is not clear whether MoFEP has received the same information for the 2011 Budget.

While multiple guidelines are prepared for budget preparation and borrowing, there remains an absence of a dedicated set of uniform, centrally publicized, consistent, and transparent guidance for MDAs and MMDAs to carry out ex ante evaluation of financial, economic and social costs/benefits of proposed projects. In addition, there is no institutionalized format for presenting and appraising of costs and benefits of project proposals. (Note 7) As a result, MDAs and MMDAs have de facto discretion to conduct any type of pre-feasibility or feasibility studies. The appraisal of specific project proposals is conducted at the MDA/MMDA level practically without participation or critical review of a central agency, such as MoFEP or NDPC.

MoFEP has undergone institutional restructuring and recently established the Public Investment Department (PID) which is responsible for conducting the central management functions for the PIM system. (Note 8) The PID department, led by a Director, comprises four units including:

- $\quad$ The Project and Financial Analysis (PFA) Unit with gate keeping and upstream investment appraisal responsibilities.

- $\quad$ The PPP Advisory Unit that will house technical specialists to support MDAs in development and management of prospective PPP projects that satisfy Government of Ghana investment priorities.

- $\quad$ The Public Entities Unit, and

- $\quad$ The Strategic Projects Unit.

However, the PID is not sufficiently resourced and lacks analytical capacity to perform its central functions in PIM. (Note 9) Therefore their role in PIM is currently confined to review PPP projects only, although its expected mandate is to review the entire portfolio.

The newly developed public private partnership policy envisions the fundamental change in appraisal. In particular, the appraisal of PPP proposal would involve multiple institutions with MoFEP playing the gate-keeping role and providing advisory services through the newly created PID. Such proposed institutional setting is an important opportunity for the PID to 
gain experience and to reflect on various modalities of project appraisal of traditional public investments.

\subsubsection{Independent Review of Appraisal}

The assessment framework suggests that it is a sound practice to subject project appraisals to an independent review. In Ghana, while the process of appraisal is delegated to MDAs and MMDAs, the independent review function remains missing, compromising the integrity of the project appraisal and exposing appraisal process to the risk of optimism bias. (Note 10) If budget committees can be set up in all MDAs (as referred to in Guidelines for the 2010-2012 Budget), the MoFEP's PID and the Capital Budget Committee may serve as an effective modality in reviewing investment project appraisals developed by spending agencies and provide further recommendations on capital spending priorities in line with the existing economic agenda. (Note 11)

\subsubsection{Budgeting and Project Selection}

The assessment framework recommends that the process of appraising and selecting public investment projects should be linked to the budget cycle. It is also important that public investment choices are linked to a development strategy (OECD. 2014. Effective Public Investment Across Levels of Government). In Ghana, there has been no consistent approach to project selection and budgeting. Project proposals are often selected on an ad-hoc basis with the budget directorate accepting projects which may not necessarily be priority projects. The MoFEP Guidelines for the 2011-13 Budget Preparation process highlight the fact that MDAs do not adequately budget for infrastructure investments and embark on projects for which there is no provision in their budget.

The Government has laid the ground for piloting a Program-Based Budgeting (PBB) framework. The PBB is expected to better align the sector medium term strategic programs with budgeting and thereby enhance the connection between the budgeting and PIM cycle. Major challenges in top down strategic planning and bottom up budgeting process include:

$\checkmark \quad$ Slow progress in the application of MTEF;

$\checkmark \quad$ Lack of credibility of the bottom up budget preparation process. As part of the 'budget negotiation' strategy, spending agencies tend to retch up their budget request in expectation that they are to be curtailed eventually (according to the PEFA 2010 report, in certain cases, budget allocation was just about half of the original amount requested);

$\checkmark$ The weakness in linking investment budget with future recurrent cost requirements despite the on-going single capital and recurrent budget process. While the recurrent costs are estimated in full feasibility studies, they serve only a formality purpose-as the information is required to be presented in the project appraisal documents. In reality, the focus of the process is more on new investment rather than recurrent costs - giving disincentives to MDAs to take recurrent cost implications of new investments into consideration. Similarly, donor financed investments do not take into consideration future maintenance costs which add another dimension of complexity to budget credibility. 


\subsubsection{Project Implementation}

The assessment framework advises prudent management of project implementation, which calls for stringent procedures and planning for both total and annual cost controls. In Ghana, there are no central guidelines for project implementation in general and for cost control in particular. It is not uncommon that MDAs fail to prepare and submit to the MoFEP detailed implementation and procurement plans, simply because such documents are not considered as mandatory for budget allocation. The institutional and procedural setting makes the MDAs focus on annual cost control only, within the given resource envelop for that particular year

On the financial management side, the slow progress in rolling out of MTEF aggravates total cost control problem. In the current system, there seems to be no tools for total cost controls. Even though the Public Procurement Act of 2003 provides overall legal framework for procurement practices and establishes competitive tendering as the preferred procurement method, single sourcing is still a common practice. In procurement, there are four areas for further reforms: (i) strengthening the legislative framework, (ii) streamlining operations, (iii) enhancing institutional development capacity, and (iv) developing transparency. (Note 12)

In project implementation, other major problems are delays and cost overruns. In some cases infrastructure projects remain incomplete for more than 10 years. This problem has been acknowledged in the MoFEP Guidelines for the 2011-2013 Budget Preparation:

"Government has noted with concern the unacceptable high number of uncompleted projects scattered all over the country. These projects, for which huge sums of scarce public resources have been used to start, are at various stages of completion and in some cases for so many years. Thus in spite of the resources spent on these projects they are still of no benefit to government."

On a positive note, the government has established a system to reverse the rising trend of accumulation of project arrears. Arrears had long been an acute problem in project implementation. But efforts were made to restore commitment controls and enhance quality of contract management. The Office of the President has instructed that all MDAs obtain MoFEP's commencement certificates before undertaking any investment activity.

\subsubsection{Project Monitoring and Adjustment}

The assessment framework suggests flexibility in the funding review process to allow changes in the disbursement profile to take account of changes in project circumstances. According to the assessment framework, each funding request should be accompanied by an updated cost-benefit analysis and a reminder to project sponsors of their accountability for the delivery of the benefits. In Ghana, to ensure accountability and transparency of institutions in the management of public investments, the country has a system that ensures both internal and external oversight. The internal control is first performed by internal auditors under the guidance of the Internal Audit Agency. Secondly, internal oversight is provided through the Policy Planning, Monitoring and Evaluation Departments (PPMEDs) in the MDAs. To ensure accountability, they are also legally obliged to present their project implementation progress reports to both internal and external scrutiny through their 
respective internal audit units and the Ghana Audit Service respectively.

However, the timeliness and quality of reports are uneven across MDAs. In addition, the Auditor General's Office lacks resources (both human and financial) to conduct performance audit, and project commencement and mid-term construction audits are not conducted. The PFA Unit within the Public Investment Division is responsible for contract management. The unit reviews the requirements for contracts to start and monitors the requests and payments of various contracts to ensure that payments are made on time and amounts requested are correct. The unit is thus able to provide reliable details on individual contracts in terms of amounts contracted, paid and outstanding arrears. The unit reviews all contract payment requests submitted by respective officers and where necessary initiates inspection on site to ascertain the level of delivery of contracts. As there is a limited number of staff and expertise within the unit, apart from coordinating with the Budget Division to undertake effective monitoring of such contracts, the unit also coordinates with the M\&E units of MDAs for a joint inspection.

MoFEP does not specifically require MDAs and MMDAs to update project documents during the construction stage and project adjustment is left to the discretion of MDAs within their available budgets. However, external factors combined with internal fiscal pressures give a good reason to MoFEP, which centrally manages the capital budgeting, to ask MDAs and MMDAs to update project information. In fact, it is normal that project plans are changed and adjusted during the construction phase due to unexpected changes in the business environment or demand forecast at the stage of project initiation and budgeting.

Constitutionally, the Auditor General's Office is mandated to conduct an independent auditing of government projects and programs. It is worth noting that the Auditor General for the past six years has been able to submit reports on financial audits of the Consolidated Fund to Parliament within the six month statutory requirement as stipulated in the FAA. However, it has not been able to undertake performance auditing of projects and programs due to inadequate capacity.

\subsubsection{Facility Operation}

The assessment framework recommends that once a project is completed, there should be a process to ensure facility management. In Ghana, there is no specific, stand-alone law on Assets Management. The overarching legal basis for assets management is contained in the FAA. This law regulates the financial management of the public sector, prescribes the responsibilities of persons entrusted with financial management in the government and seeks to ensure the effective and efficient management of revenue, expenditure, assets, liabilities and the resources of government. (Note 13)

The 2004 Financial Administration Regulations impose on each MDA to have an inventory of public assets acquired and maintained. However, this legal provision is not being enforced systematically and consistently in all MDAs. Even though the responsibility for maintaining a composite record of public assets is vested with the Controller and Accountant General, the Controller has no central record of all the assets acquired and maintained by the Government. 


\subsubsection{Project Evaluation}

According to the assessment framework, a desirable feature of a PIM system is a basic completion review and ex-post evaluation of finished projects. In Ghana, government financed capital spending is not subject to formal ex-post evaluation. The absence of institutional requirement and setting to conduct this function undermines accountability and creates missed opportunity to draw lessons for further improvements in the next project management cycle. It thereby creates the tendency for perpetuating deficiencies across various stages of project design, appraisal, selection, implementation and supervision.

\section{Conclusion and Policy Recommendations}

This paper contributes to the growing literature on the analysis of the efficiency and efficacy of public investment systems in Africa. By using an indicator based framework developed by Rajaram et al. (2010), it analyzes the institutional strengthen of PIM system in Ghana. Over the past decade, Ghana has made important strides towards improving the quality of PFM systems in general and PIM in particular. Successful roll-out of the program-based budgeting, smooth functioning of the GIFMIS, enhanced transparency and accountability and strengthened legal framework for PFM will all improve the efficiency and efficacy of the PIM system. In addition, the MoFEP would need to establish a well-grounded legal and regulatory framework and embark upon fundamental institutional restructuring to address the missing functions in capital budgeting. The establishment of the PID and issuance of the national policy on PPP with concrete directions for sound management of the use of public resources lay a good ground for further PIM reforms.

Nevertheless, compliance with the established legal framework and guidelines for preparation of budget proposals remains weak-while a number of critical functions in PIM, such as public investment proposal screening, appraisal, monitoring and evaluation, either exist largely in formality or are completely missing. Appendix 1 presents the summary of gap analysis, comparing the desirable features of a well-functioning PIM and the current status of the PIM in Ghana. While improvements can be made across all stages of the public investment management chain, the diagnostic assessment concludes that actions to strengthen upstream appraisal and selection of projects, and the monitoring of their execution could entail immediate improvements in the quality of investment projects.

Additional follow up measures listed in Appendix 1 can be classified in two groups: over the short and long-term.

In the short term, enhancing the quality of national strategic documents and the inter-linkages among them (i.e., PRSP, MTEF, and PIP) is important. Project preparation and financing stage requires effective coordination between MoFEP and NDPC in terms of planning and development program costing. Such clarification of the national planning mandate of the NDPC should go in parallel with revamping and reorganizing the economic functions of the MoFEP. On the MoFEP side, it is critical to have the right skill sets in the core areas of its mandates. As the World Bank policy note on Strengthening Central Finance Functions in Ghana from 2010 indicates, the rollout of the Economic Strategy Branch will specifically 
require a major change in the staffing requirements and effective coordination between the two branches (finance and economic strategy-including planning) of the MoFEP. For example, as the program budgeting implementation advances there is a need for strengthening of the economic assumptions and projections that underpin preparation of the annual budget and the MTEF.

From its part, the MoFEP could (1) revise the guidelines for budget preparation to include the simplified and concrete provisions on institutional arrangement and procedures for capital budgeting; (2) articulate, publicize and communicate the clear mandates for the new PID to all other stakeholders including the MDAs/MMDAs, business community, the public and development partners. Currently the guidelines for capital budgeting are vague, imprecise, and often regarded by MDAs as optional. In particular, the requirement for cost benefit/cost effectiveness analysis is proposed without referring to specific methodologies and scope of projects that are subject to such rigorous exercise. A Capital Budget Committee was proposed to develop and implement appropriate approach to project appraisal, but it has yet to materialize. The guidelines need to be revised in consultation with line ministries to include a methodology for appraisal.

The most cost-effective way to gain efficiency in PIM for Ghana is to introduce a mandatory threshold for appraisal as complimentary to the set of revised guidelines for project cycle management. The practice is commonly applied in more advanced PIM systems (e.g., UK, Ireland, or even Vietnam). A project of a scale higher than the established threshold should be subject to more rigorous appraisal and even to independent review consisting of multi-sectoral expertise.

Over the medium to long term, certain reform activities could be undertaken focusing on staffing, capacity enhancement for the MoFEP (the PID, in particular), NDPC, and MDAs/MMDAs in preparing and implementing dedicated guidelines for PIM. The PID in coordination with other departments of MoFEP, the NDPC, and other stakeholders should take the lead in preparing the detailed central guidelines for the entire project cycle. The guidelines on integrated PIM should be published as a dedicated set of documents, separate from the annual budget preparation guidelines. They need to be clear, transparent and practical (i.e., technically commensurate with the prevailing institutional capacity).

In addition, efforts and resources are to be dedicated to extensive training in project appraisal, monitoring and evaluation at both the central agency level (MoFEP, NDPC) and spending agency level. Enhancing transparency across different stages of the PIM is the cornerstone for communication with all stakeholders and an essential ingredient for raising the public awareness. The wider public - the ultimate beneficiaries of capital investments - should be given sufficient information in a timely manner about the budget decisions in general and the choice of public financed projects in particular. Only with such information, they could be empowered to raise questions and demand for accountability frompublic institutions and individuals concerned. Transparency would specifically benefit the PID to engage effectively with spending agencies-communicating across stakeholders and exercising its mandated gate-keeping function. 
Ghana has made steady progress in improving the open budget index (OBI) scores, from 42 in 2006 to 54 in 2010. (Note 14) This has subsequently dropped to a score of 51 in 2015. Budget speeches and different guidelines for loan financing and budget preparation are readily available in the MoFEP website. However, the deepening process requires credible-not just formational but functional-planning, appraisal and selection of public investment proposals which are currently lacking. The inherent connection between availability of appropriate forms and functions in PIM and making them widely known to the public is directly related to the current debate on reviving the public investment program (PIP). Information is critical for beneficiaries and Civil Society Organizations to hold sectors and implementing agencies accountable.

In preparation of the new PIP, Ghana could benefit from lessons from its own failures in the past and those elsewhere. The MoFEP as the champion in PIM reforms could identify the clear stages and regulatory procedures linking the PIP with the overall MTEF and annual budgeting. It is worth emphasizing that the PIP process is an integrated part of but not a parallel undertaking to the overall national planning and PIM. The success of PIP hinges on some factors:

$\checkmark$ First, there must be credible institutional arrangements and a rigorous process in vetting project proposals to be included in PIP. The process is related to the revision of the guidelines for capital planning as part of overall budget preparation in the short run and the preparation of a dedicated, uniform set of guidelines for PIM in the medium to long term (as mentioned above).

$\checkmark$ Second, it is critical to ensure the harmonization between PIP and MTEF on the one hand and PIP and disciplinary budgeting process on the other. Otherwise, like the mistake made in the past, the PIP would be presented again as simply shopping list without much regard to it in the budgeting process.

$\checkmark$ Third, budget discipline requires that only those projects listed in PIP are to be considered for financing hence inclusion into the budget.

$\checkmark \quad$ Fourth, the selection process and the final list of PIP (updated periodically) as well as the budget process linked to it have to be transparent so that the public can scrutinize on its usefulness and application.

$\checkmark$ Fifth, a database of projects, from the appraisal stage toexecution and operation should be developed. The database should integrated in GIFMIS so as to facilitate the process of budgeting, execution and monitoring.

Top down and external pressure on the quality of project implementation requires reform measures that would empower the oversight function of MoFEP and the Auditor General's Office. Support should be given to equip the Auditor General's Office with sufficient capacity to organize and conduct annual review of project procurement and performance from a small sample of large-scale projects under construction. In the same vein, the Finance Committee of Parliament-mandated to review and recommend the approval of loans for public investment — should also be empowered with timely flow of information, adequate supporting 
resources and access to expert advisers to appropriately exercise its authority.

\section{References}

Abiad, A., Furceri, D., \& Topalova, P. (2015). The Macroeconomic Effects of Public Investment: Evidence from Advanced Economies. IMF Working Paper 15/95.

Barma, N., Kaiser, K., Le, T. M., \& Vinuela, L. (2012). Rents to Riches? The Political Economy of Natural Resource-Led Development. The World Bank.

Collier, P., \& Venables, A. J. (2008). Managing the Exploitation of Natural Assets: Lessons for low income countries. [Online] Available: http://users.ox.ac.uk/ econpco/research/pdfs/ManagingtheExploitationofNaturalAssets.pdf

Flyvbjerg, B. (2009). Oxford Review of Economic Policy, 25(3), 344-367. http://dx.doi.org/10.1093/oxrep/grp024

IMF. (2014). World Economic Outlook. Legacies, Clouds, Uncertainties, Chapter 3: Is It Time for an Infrastructure Push? The Macroeconomic Effects of Public Investment. [Online] Available: https://www.imf.org/external/pubs/ft/wp/2015/wp1595.pdf

IMF. (2015). Making Public Investment More Efficient. [Online] Available: http://www.imf.org/external/np/pp/eng/2015/061115.pdf

Lledo, V. D., Yackovlev, I., \& Gadene, L. (2011). A Tale of Cyclicality, Aid Flows and Debt: Government Spending in Sub-Sharan Africa. Journal of African Economies, 20(5), 823-849. http://dx.doi.org/10.1093/jae/ejr022

Ministry of Finance and Economic Planning, Ghana. (2011). Joint Review of Public Expenditure and Financial Management. Accra, Ghana.

OECD. (2014). Effective Public Investment across Levels of Government. [Online] Available: http://www.oecd.org/gov/regional-policy/Principles-Public-Investment.pdf

Rajaram, A., Le, T. M., James, B., \& Natalyia, B. (2010). A Diagnostic Framework for Assessing Public Investment Management. World Bank Policy Research Working Paper No. 5397.

Rajaram, A., Le, T. M., Kaiser, K., Kim, J. H., \& Frank, J. (Eds). (2014). The Power of Public Investment Management: Transforming Resources into Assets for Growth. World Bank. http://dx.doi.org/10.1596/978-1-4648-0316-1

Riasi, A., \& Pourmiri, S. (2016). Examples of Unsustainable Tourism in Middle East. Environmental Management and Sustainable Development, 5(1), 69-85. http://dx.doi.org/10.5296/emsd.v5il.8705

Thornton, J. (2008). Explaining Procyclical Fiscal Policy in African Countries. Journal of African Economies, 17(93), 451-464. 
Warner, A. (2014). Public Investment as an Engine of Growth. IMF Working Paper, 14/148 (Washington: International Monetary Fund). [Online] Available: https://www.imf.org/external/pubs/ft/wp/2014/wp14148.pdf

World Bank and IMF. (2011). Ghana Joint IDA-IMF Staff Advisory Note on the Ghana Shared Growth and Development Agenda. Washington D.C.

\section{Notes}

Note 1. The field came on-stream in December 2010. In 2015, the average production was 102,600 barrels per day.

Note 2. See Ghana Joint IDA-IMF Staff Advisory Note on the Ghana Shared Growth and Development Agenda, World Bank and International Monetary Fund, July 2011, Washington D.C.

Note 3. Between 2007 and 2011, ODA financed about 25 percent of total public investment, and external non concessional borrowing another 20 percent.

Note 4. In December 2011, the Government borrowed US\$3.0 billion from the China Development Bank at non concessional terms. In comparison, Ghana has been borrowing externally US\$480 million on average every year since 2007 at non concessional terms.

Note 5. See MoFEP, 2011, Joint Review of Public Expenditure and Financial Management, October, Accra.

Note 6. According to the MoFEP's Guidelines for the Preparation of the 2010-2012 Budget Proposals (July 2009), all funding requests for infrastructure and large capital projects by MDAs would be subject to rigorous appraisal and review by the CBC. Structurally, the CBC is an inter-ministerial task team to be set up at MoFEP and is formally responsible for making recommendations for selection and financing of such projects and programs.

Note 7. The literature on ex ante estimates of costs and benefits of large infrastructure projects is full of examples with substantial cost underestimates as well as significant benefit overestimates, rendering more emphasis on the accuracy of cost benefit analyses of project. See Flyvbjerg, Bent. Oxford Review of Economic Policy, Volume 25, Number 3, 2009, pp.344-367.

Note 8. Apart from the newly established PID, the Budget Division of MoFEP has a key role to play in PIM. It holds 'the purse' and ensures that funds are allocated for the execution of public investment projects in the country. Budget Division also monitors the release of funds to the various MDAs and MMDAs in collaboration with the Accountant General's Department.

Note 9. When we visited the PID in November 2011, the PFA unit has only seven staff in total including two senior and five junior staff. The Public Private Partnership (PPP) unit had only three consultants (financed by DFID). The Public Entities Unit had two senior and one 
junior staff. The Strategic Projects unit had not recruited any staff yet.

Note 10. Optimism bias is the demonstrated systematic tendency for people to be overly optimistic about the outcome of planned actions. This includes over-estimating the likelihood of positive events and under-estimating the likelihood of negative events.

Note 11. According to the July 2009 Budget Guideline for the 2010-2012 budget proposals, in addition to the planned establishment of the Capital Budget Committee as a central agency or gate-keeper at MoFEP, a budget committee is supposed to be set up at each MDA. The proposal if implemented properly would serve as a good model of combined top-down, bottom-up screening, appraising, and conducting independent review of project proposals by spending agencies.

Note 12. The Joint Review of Public Expenditure and Financial Management 2011.

Note 13. Part IV of the Act-Sections 30-37-deals with recording, management, and control of Government stores by all government entities; and part V deals with the accounting and auditing of the assets, inter alia.

Note 14. IBP, 2010, Open Budgets Transform Lives: The Open Budget Survey 2010.

\section{Appendix}

Appendix 1. Gap analysis of the PIM systems in Ghana

\begin{tabular}{|c|c|c|}
\hline $\begin{array}{l}\text { Stage of Public } \\
\text { Investment }\end{array}$ & $\begin{array}{l}\text { Desirable Institutional Arrangement (As framed in Rajaram et } \\
\text { al., 2010) }\end{array}$ & Current Status of the PIM in Ghana \\
\hline $\begin{array}{l}\text { 1. Strategic } \\
\text { Guidance and } \\
\text { Preliminary } \\
\text { Screening }\end{array}$ & $\begin{array}{l}\text { - } \quad \text { Published development strategy or vision statement which } \\
\text { has unambiguous authority. } \\
\text { - Centralized approval by planning or finance ministry (or } \\
\text { delegated) for developing proposals/explicit ministry level } \\
\text { justification with strategy. } \\
\text { - Clarity of project objectives in terms of outputs and } \\
\text { outcomes. } \\
\text { - Consideration of alternative approaches to objectives. }\end{array}$ & $\begin{array}{l}\text { - } \quad \text { GSGDA for 2010-2013 developed. Guidance notes issued by } \\
\text { NDPC for MMDAs to develop and cost their sector strategies. Based on } \\
\text { sectoral and sub-national medium term plans, annual work plans are } \\
\text { prepared and fed into the three-year rolling budget (MTEF). But } \\
\text { divergence between strategy-planning and budgeting remains due to the } \\
\text { low quality of costing of sector strategies. } \\
\text { - MoFEP is only at the very initial stage of development of a PIP in } \\
\text { conjunction with NDPC. } \\
\text { - But still no established process for screening of projectproposals. }\end{array}$ \\
\hline $\begin{array}{l}\text { 2. Formal } \\
\text { Project } \\
\text { Appraisal }\end{array}$ & $\begin{array}{l}\text { - Publicized and transparent guidance, backed by effective } \\
\text { training and deployment of staff for project design and appraisal } \\
\text { (including stakeholder consultation in project design). } \\
\text { - } \quad \text { Application of guidance in project appraisal. }\end{array}$ & $\begin{array}{l}\text { - Project appraisal highly decentralized without an established formal } \\
\text { process. } \\
\text { - MoFEP has issued multiple guidelines for budget preparation, } \\
\text { public borrowing and project selection. MoFEP has undergone } \\
\text { institutional restructuring with the newly established PID. However PID is } \\
\text { not sufficiently resourced and lacks analytical capacity to perform its } \\
\text { central functions in PIM. } \\
\text { - Absence of a dedicated set of uniform, centrally publicized, } \\
\text { consistent, and transparent guidance for MMDAs to carry out ex ante } \\
\text { evaluation of financial, economic and social costs/benefits of proposed } \\
\text { projects. }\end{array}$ \\
\hline $\begin{array}{l}\text { 3. Independent } \\
\text { Review of } \\
\text { Appraisal }\end{array}$ & $\begin{array}{l}\text { - Independent checks to ensure objectivity and quality of } \\
\text { appraisals. } \\
\text { - Disciplined completion of project appraisals prior to budget. } \\
\text { - Identifying and maintaining an inventory of appraised } \\
\text { projects ranked by priority for budgetary consideration. } \\
\text { - Clarity of roles between projects which are minor and may be } \\
\text { dealt with at the departmental level, and those requiring additional } \\
\text { appraisal. }\end{array}$ & $\begin{array}{l}\text { While appraisal completely delegated to MMDAs, the independent } \\
\text { review function remains missing, compromising the integrity of the } \\
\text { project appraisal and exposing appraisal process to the risk of optimism } \\
\text { bias. }\end{array}$ \\
\hline
\end{tabular}




\section{Macrothink}

Case Studies in Business and Management

ISSN 2333-3324

2016, Vol. 3, No. 2

\begin{tabular}{|c|c|c|}
\hline $\begin{array}{l}\text { 4. Project } \\
\text { Budgeting } \\
\text { and Selection }\end{array}$ & $\begin{array}{l}\text { - Transparent criteria for selecting projects with reference to } \\
\text { policy objectives at ministerial level. } \\
\text { - } \quad \text { Well structured budget preparation process with scope to } \\
\text { integrate investment and recurrent implications of projects. } \\
\text { - } \quad \text { Effective gate-keeping to ensure that only appraised and } \\
\text { approved projects are selected for budget financing. } \\
\text { - } \quad \text { Ensuring adequate financing for selected projects, including } \\
\text { recurrent needs on completion. }\end{array}$ & $\begin{array}{l}\text { - Absence of a consistent approach to project selection and } \\
\text { budgeting. } \\
\text { - Project proposals often selected on an ad-hoc basis with the budget } \\
\text { directorate accepting projects which may not necessarily be priority } \\
\text { projects. } \\
\text { - MoFEP concerns about the persistent problem that MDAs do not } \\
\text { adequately budget for infrastructure investments while embarking on } \\
\text { projects for which there is no provision in their budget. }\end{array}$ \\
\hline $\begin{array}{l}\text { 5. Project } \\
\text { Implementation }\end{array}$ & $\begin{array}{l}\text { - } \\
\text { - } \\
\text { contracting. } \\
\text { - } \quad \text { Timely implementation in line with guidelines. } \\
\text { - } \quad \text { Timely implementation reports on major projects. } \\
\text { - } \quad \text { Effective budgeting for selected projects. }\end{array}$ & $\begin{array}{l}\text { - Absence of central guidelines for project implementation and for } \\
\text { cost control. MDAs often fail to prepare and submit to the MoFEP detailed } \\
\text { implementation and procurement plans, simply because such documents } \\
\text { are not considered as mandatory for budget allocation. MDAs focus on } \\
\text { annual cost control only. } \\
\text { - The Public Procurement Act } 2003 \text { establishes competitive } \\
\text { tendering as the preferred procurement method but fails to curb the } \\
\text { continued problems with project delays and cost overrun. } \\
\text { • } \quad \text { Arrears had long been an acute problem. Recent efforts to restore } \\
\text { commitment controls (e.g., requirement to obtain MoFEP's } \\
\text { commencement certificates) were successful to stop the rising trend of } \\
\text { accumulation of project arrears since } 2011 \text {. }\end{array}$ \\
\hline $\begin{array}{l}\text { 6. Project } \\
\text { Adjustment }\end{array}$ & Active monitoring. & $\begin{array}{l}\text { While a formal system for internal and external oversight exists, the } \\
\text { timeliness and quality of internal audit reports are uneven across agencies. } \\
\text { The AG's Office lacks resources to conduct performance audit, and } \\
\text { project commencement and mid-term construction audits are not } \\
\text { conducted. } \\
\text { - The PFA Unit (within the PID) coordinates with Budget Division to } \\
\text { undertake monitoring of contracts and with the M\&E units of MDAs to } \\
\text { conduct sampled joint inspection. But they have limited staffing and } \\
\text { expertise. } \\
\text { - } \quad \text { MDAs not required updating project documents during } \\
\text { construction. } \\
\text { - } \quad \text { Project adjustment is left to the discretion of MDAs within their } \\
\text { available budgeting. }\end{array}$ \\
\hline $\begin{array}{l}\text { 7. Facility } \\
\text { Operation }\end{array}$ & $\begin{array}{ll}- & \text { Asset registry. } \\
\text { - } & \text { Facility operation. }\end{array}$ & $\begin{array}{l}\text { - The Financial Administration Regulations impose on each MDA to } \\
\text { have an inventory of public assets acquired and maintained. This legal } \\
\text { provision is not being complied with systematically and consistently in all } \\
\text { MDAs. }\end{array}$ \\
\hline $\begin{array}{l}\text { 8. } \\
\text { Evoject } \\
\text { Evaluation }\end{array}$ & $\begin{array}{l}\text { Formal institutional arrangements for ex post evaluation of } \\
\text { projects/programs with feedback into future project designs. }\end{array}$ & $\begin{array}{l}\text { - Government financed capital spending is not subject to formal } \\
\text { ex-post evaluation. }\end{array}$ \\
\hline
\end{tabular}

\section{Copyright Disclaimer}

Copyright for this article is retained by the author(s), with first publication rights granted to the journal.

This is an open-access article distributed under the terms and conditions of the Creative Commons Attribution license (http://creativecommons.org/licenses/by/3.0/). 